\title{
A Review: Garlic Effects on the Cardiovascular System
}

\author{
Madaj Paul M* and Budoff Matthew J \\ Los Angeles Biomedical Institute at Harbor-UCLA, USA
}

Submission: March 09, 2017; Published: May 08, 2017

*Corresponding author: Madaj Paul M, Los Angeles Biomedical Institute at Harbor-UCLA, USA, Email: paul_madaj@yahoo.com

\begin{abstract}
Coronary Artery Disease (CAD) is one of the leading causes of morbidity and mortality in the world. Detection as well as modification of risk factors for cardiovascular disease (CVD) has been the topics research over several decades. Multiple drugs have been studied and used in clinical practice with people seeking "natural" alternatives. When evaluating for optimal treatment options and the multiple risk factors associated CAD (e.g. diabetes, hypertension, etc.), garlic can play a prominent role. Studies have shown promising results in treating hypertension, altering the lipid profile, prevention and even treatment of coronary atherosclerosis and its systemic anti-oxidant properties.
\end{abstract}

Garlic also has positive effects outside the cardiovascular system (e.g. immune system). It can be used stand-alone or as an adjunct to current medical therapy. No clinically significant side effects have been reported, thus providing a safe treatment option to be considered. Coronary Artery Disease (CAD) is one of the leading causes of morbidity and mortality in the world. Detection as well as modification of risk factors for cardiovascular disease (CVD) has been the topics research over several decades. Multiple drugs have been studied and used in clinical practice with people seeking "natural" alternatives. Some well-known alternatives include pomegranate juice, green tea, and garlic [13]. Our focus will be on the utility of garlic. Multiple myths and beliefs over thousands of years exist where garlic is a key element in treatment and prevention of illness (e.g. common cold) as well as increasing strength and endurance.

It was even used as a performance enhancer in ancient Olympics. In recent years, garlic has been a major area of focus in prevention and treatment of CAD and associated risk factors. We will review the role garlic has played in the modification of hypertension, hyperlipidemia, inflammatory markers and coronary artery calcium [3-7]. Garlic can provide an alternative to conventional medication without significant side effects.

Abbreviations: TAG: Triglycerides; RLPs : Remnant Lipoproteins; CAD: Coronary Artery Disease; CVD: Cardiovascular Disease; CAC: Coronary Artery Calcium; LAP: Low Attenuated Plaque

\section{Lipid Profile}

Multiple studies have implemented garlic's effect of the lipid profile. Of all the components of the lipid panel, well known are the effects of LDL, triglycerides, total cholesterol and their role in CAD. In a meta-analysis by Reinhart et al examined the role of garlic on reduction of total cholesterol, driven mostly by reduction in triglycerides (TAG) [8]. In fact, the component most potent for creating a proinflamatory state is the remnant lipoprotein cholesterol [9]. Remnant lipoproteins (RLPs) are products of partially catabolized chylomicrons and very-lowdensity lipoprotein, from which some triglycerides have been removed, that are found to be highly arythmogenic.

Remnants are known to cross the endothelial barrier and due to their larger size, they carry 5 to 20 times as much cholesterol per particle as LDL [10]. Remnant (apo A1 remnant ratio) association with short and intermediate term mortality was shown to be a significant predictor, especially in women above 50 years of age [11]. In a study by de Vries et al. [12], chylomicrons were shown to be more potent in causing inflammation when compared to hypertriglyceridemia $[12,13]$. Of note, Matsuo et al showed remnant lipoprotein levels being linked to coronary plaque vulnerability, which is characterized by high necrotic and low fibrotic components [14].

Thus, remnant lipoproteins are well known and becoming more established as risk factors for CAD [13]. Nakamura et al. [15] was also able to establish the role of insulin resistance as also contributing to postprandial hyperlipidemia, especially in those with CAD, thus possibly requiring more aggressive treatment of such states $[15,16]$. Well known at this time the various treatment options and preventative measure for hyperlipidemia (e.g. diet, exercise, statins, fibrates, etc.) 


\section{Hypertension}

Hypertension is also another well-known cardiovascular disease risk factor. Garlic has shown to have a role in treatment of hypertension. Reid et al. [17] in the AGE at Heart trial was able to establish a direct link of garlic on central and peripheral hypertension; as an adjunct or stand-alone treatment. Mean blood pressure was significantly reduced by $5.0 \pm 2.1 \mathrm{mmHg}$ $(\mathrm{P}=0.016)$ systolic, and in responders by $11.5 \pm 1.9 \mathrm{mmHg}$ systolic and $6.3 \pm 1.1 \mathrm{mmHg}$ diastolic compared to placebo $(\mathrm{P}<0.001)[17,18]$. Thus, establishing a role in the reduction of both central and peripheral blood pressure.

Xiong et al. [19] in a meta-analysis on 7 randomized, placebo controlled trials since 2014 was able to establish a similar link on the role of garlic on hypertension. This metaanalysis revealed a significant lowering effect of garlic on both systolic BP (WMD: -6.71mmHg; 95\% CI: -12.44 to -0.99 ; P=0.02) and diastolic BP (WMD: $-4.79 \mathrm{mmHg}$; $95 \%$ CI: -6.60 to -2.99 ; P $<0.00001$ ). Hosseini et al. [20] was able to establish a similar link in addition to the effect on lipid profile as well as antidiabetic effect. Despite this link, more research is required to establish garlic as a stand along treatment of hypertension. At this time, it can be used as an adjunct to conventional means.

\section{Coronary Atherosclerosis}

Garlic has also to have a role in prevention and treatment of coronary atherosclerosis. Multiple randomized trials were able to demonstrate a significant reduction in Coronary Artery Calcium (CAC) progression [4]. This is demonstrated through its direct role on the atherosclerotic process [21,22]. In a study by Budoff et al. \& Ahmadi et al. [21,22], aged garlic extract supplemented with B vitamins, folic acid and L-arginine had a positive role in not only reducing atherosclerosis but improvement in oxidative biomarkers and vascular function.

Matsumoto et al. [23] was able to establish the role of aged garlic extract and its role in coronary plaque. The \% low attenuated plaque (LAP) change in the study was significantly reduced in the AGE group compared with the placebo group $(-1.5 \% \pm 2.3 \%$ compared with $0.2 \% \pm 2.0 \%, P=0.0049)$. Multivariable linear regression analysis found a beneficial effect of AGE on \%LAP regression ( $\beta$ : $-1.61 ; 95 \%$ CI: $-2.79,-0.43$; $\mathrm{P}=0.008$ ) [23]. Thus, demonstrating the inhibitory role on the progression of non-calcified plaque. Recently, Madaj et al. [24] demonstrated garlic's positive effects on coronary artery calcium, to supplement those earlier studies. Karagodin et al. [25] after evaluation of the Atherosclerosis Monitoring and Atherogenicity Reduction Study was able to show reduction of cardiovascular risk after use of garlic.

Twelve-month treatment lowered 10-years prognostic risk of coronary artery disease by $13.2 \%$ in men $(\mathrm{P}=0.005)$, and by $7.1 \%$ in women $(\mathrm{P}=0.040)$. Ten-year prognostic risk of acute myocardial infarction and sudden coronary death was lowered by $26.1 \%$ in men $(\mathrm{P}=0.025)$ [25]. Studied here was also the progression of carotid atherosclerosis in asymptomatic men which can one can indirectly infer its effect on coronary artery atherosclerosis. Mahdavi-Roshan et al. [26] were able to demonstrate lack of progression of carotid intima media thickness with the use of garlic. After 3 months of taking garlic tablets, CIMT values had minor variations $(0.009 \pm 0.007 \mathrm{~mm}$ reduction from baseline), while in the placebo group, an increase in CIMT values was observed $(0.04 \pm 0.01 \mathrm{~mm}$ increase from baseline). Zeb et al. \& Ahmadi et al. [27,28] were also able to demonstrate the use of garlic in the prevention of coronary artery disease. Thus, garlic has been shown to have positive effects on coronary atherosclerosis either as a stand-alone treatment or adjunct to conventional therapy.

\section{Inflammatory Markers}

Garlic has been found in studies to have a prominent role in affecting inflammatory markers. Despite its systemic antioxidant effects, we will limit our discussion to its effects on the cardiovascular system. This link has been demonstrated predominantly by decreased levels of CRP and Il-17A27, thus allowing garlic to have a direct role on the atherosclerotic process $[21,22]$. In a study by Budoff et al \& Ahmadi et al. $[21,22]$, aged garlic extract supplemented with B vitamins, folic acid and L-arginine had a positive role in not only reducing atherosclerosis but improvement in oxidative biomarkers and vascular function. Ried et al. [17] in the AGE at Heart trial were also able to demonstrate a reduction in inflammatory markers. $\mathrm{TNF} \alpha$ was reduced in the garlic group compared to placebo with borderline significance $(\mathrm{P}=0.05)$, while changes in IL$1 \beta$ were not significant, but greater reduction was observed in the garlic group [17]. Results to date are very promising in establishing this relationship, but further work is needed to validate and expand on the progress made on the link between garlic and its anti-oxidant properties.

\section{Conclusion}

When evaluating for optimal treatment options and the multiple risk factors associated CAD (e.g. diabetes, hypertension, etc.), garlic can play a prominent role. Studies have shown promising results in treating hy pertension, altering the lipid profile, prevention and even treatment of coronary atherosclerosis and its systemic anti-oxidant properties. Garlic also has positive effects outside the cardiovascular system (e.g. immune system). It can be used stand-alone or as an adjunct to current medical therapy. No clinically significant side effects have been reported, thus providing a safe treatment option. Despite the promising results, further studies are needed along to evaluate and validate the role of garlic on the various components of the atherosclerotic process, especially on its role in event reduction. 


\section{References}

1. Ohmori R, Kondo K, Momiyama Y (2014) Antioxidant beverages: green tea intake and coronary artery disease. Clin Med Insights Cardiol 8(Suppl 3): 7-11.

2. De Nigris F, Williams-Ignarro S, Lerman LO, Crimi E, Botti C, et al. (2005) Beneficial effects of pomegranate juice on oxidation-sensitive genes and endothelial nitric oxide synthase activity at sites of perturbed shear stress. Proc Natl Acad Sci U S A. 102(13): 4896-4901.

3. Varshney R, Budoff MJ (2016) Garlic and Heart Disease. J Nutr 146(2): 416S-421S

4. Hom C LY, Budoff MJ (2015) The Effects of Aged Garlic Extract on Coronary Artery Calcification Progression. J Nutr Food Sci DOI 10.4172/2155-9600.S5-005, p. 1-5.

5. Budoff MJ, Takasu J, Flores FR, Niihara Y, Lu B, et al. (2013) Inhibiting progression of coronary calcification using Aged Garlic Extract in patients receiving statin therapy: a preliminary study. Prev Med 39(5): 985-991.

6. Larijani VN, Ahmadi N, Zeb I, Khan F, Flores F, et al. (2013) Beneficial effects of aged garlic extract and coenzyme Q10 on vascular elasticity and endothelial function: the faith randomized clinical trial. Nutrition 29(1): 71-75.

7. Budoff MJ, Gul KM, Lui ST, Flores FR, Tiano J, et al. (2009) An aged Allium sativum (garlic) extract preparation retards the progression of atherosclerosis. Focus Altern Compl Ther 14(4): 287-288.

8. Reinhart KM, Talati R, White CM, Coleman CI (2009) The impact of garlic on lipid parameters: a systematic review and meta-analysis. Nutr Res Rev 22(1): 39-48.

9. Kim JY, Park JH, Jeong SW, Schellingerhout D, Park JE, et al. (2011) High levels of remnant lipoprotein cholesterol is a risk factor for large artery atherosclerotic stroke. J Clin Neurol 7(4): 203-209.

10. Ruth McPherson (2013) "Non-(HDL-C + LDL-C)" as a coronary artery disease risk factor. J Am Coll Cardiol 61(4): 437-439.

11. May HT, Nelson JR, Kulkarni KR, Anderson JL, Horne BD, et al. (2013) A new ratio for better predicting future death/myocardial infarction than standard lipid measurements in women $>50$ years undergoing coronary angiography: the apolipoprotein A1 remnant ratio (Apo A1/ [VLDL(3)+IDL]). Lipids Health Dis 12: 55.

12. De Vries MA, Klop B, Alipour A, Van de Geijn GJ, Prinzen L, et al. (2015) In vivo evidence for chylomicrons as mediators of postprandial inflammation. Atherosclerosis 243(2): 540-545.

13. Mashimo Y, Maeda T, Teramoto T (2012) Dyslipidemia. Nihon Rinsho $70(5): 852-856$

14. Matsuo N, Matsuoka T, Sumire O, Hiroyasu Y, Akinobu Kato, et al. (2015) Impact of Remnant Lipoprotein on Coronary Plaque Components. J Atheroscler Thromb 22(8): 783-795.

15. Nakamura A, Monma Y, Kajitani S, Noda K, Nakajima S, et al. (2016) Effect of glycemic state on postprandial hyperlipidemia and hyperinsulinemia in patients with coronary artery disease. Heart Vessels 31(9): 1446-1455.

16. Nakamura A, Monma Y, Kajitani S, Kozu K, Ikeda S, et al. (2015) Different postprandial lipid metabolism and insulin resistance between nondiabetic patients with and without coronary artery disease. J Cardiol 66(5): 435-444

17. Ried K, Travica N, Sali A (2016) The effect of aged garlic extract on blood pressure and other cardiovascular risk factors in uncontrolled hypertensives: the AGE at Heart trial. Integr Blood Press Control 9: 9-21.

18. Ried K (2016) Garlic Lowers Blood Pressure in Hypertensive Individuals, Regulates Serum Cholesterol, and Stimulates Immunity: An Updated Meta-analysis and Review. J Nutr 146(2): 389S-396S.

19.Xiong XJ, Wang PQ, Li SJ, Li XK, Zhang YQ et al. (2015) Garlic for hypertension: A systematic review and meta-analysis of randomized controlled trials. Phytomedicine 22(3): 352-361.

20. Hosseini A, Hosseinzadeh H (2015) A review on the effects of Allium sativum (Garlic) in metabolic syndrome. J Endocrinol Invest 38(11): 1147-1157.

21. Budoff MJ, Ahmadi N, Gul KM, Liu ST, Flores FR, et al. (2009) Aged garlic extract supplemented with B vitamins, folic acid and L-arginine retards the progression of subclinical atherosclerosis: a randomized clinical trial. Prev Med 49(2-3): 101-107.

22. Ahmadi N, Tsimikas S, Hajsadeghi F, Saeed A, Nabavi V, et al. (2010) Relation of oxidative biomarkers, vascular dysfunction, and progression of coronary artery calcium. Am J Cardiol 105(4): 459-466.

23. Matsumoto S, Nakanishi R, Li D, Alani A, Rezaeian P, et al. (2016) Aged Garlic Extract Reduces Low Attenuation Plaque in Coronary Arteries of Patients with Metabolic Syndrome in a Prospective Randomized Double-Blind Study. J Nutr 146(2): 427S-432S.

24. Madaj PM, Nelson JR, Li D, Flores F, Budoff MJ (2016) Garlic Effects on Coronary Artery Calcium. Int J Cardiovasc Res 6: 1-3.

25. Karagodin VP, Sobenin IA, Orekhov AN (2016) Antiatherosclerotic and Cardioprotective Effects of Time-Released Garlic Powder Pills. Curr Pharm Des 22(2): 196-213.

26. Mahdavi-Roshan M, Zahedmehr A, Mohammad-Zadeh A, Sanati HR, Shakerian F, et al. (2013) Effect of garlic powder tablet on carotid intima-media thickness in patients with coronary artery disease: a preliminary randomized controlled trial. Nutr Health 22(2): 143-155.

27. Ahmadi I, Ahmadi N, Nasir K, Kadakia J, Larijani VN, et al. (2012) Aged garlic extract and coenzyme Q10 have favorable effect on inflammatory markers and coronary atherosclerosis progression: A randomized clinical trial. J Cardiovasc Dis Res 3(3): 185-190.

28. Ahmadi N, Nabavi V, Hajsadeghi F, Zeb I, Flores F, et al. (2013) Aged garlic extract with supplement is associated with increase in brown adipose, decrease in white adipose tissue and predict lack of progression in coronary atherosclerosis. Int J Cardiol 168(3): 23102314. 
(C) (i) This work is licensed under Creative DOI: $10.19080 /$ JOCCT.2017.05.555658

\section{Your next submission with Juniper Publishers will reach you the below assets}

- Quality Editorial service

- Swift Peer Review

- Reprints availability

- E-prints Service

- Manuscript Podcast for convenient understanding

- Global attainment for your research

- Manuscript accessibility in different formats ( Pdf, E-pub, Full Text, Audio)

- Unceasing customer service

Track the below URL for one-step submission https://juniperpublishers.com/online-submission.php 